\title{
Hubungan Karakteristik, Pengetahuan dan Keterampilan Hidup ( Life Skill) Remaja tentang Perilaku Berpacaran
}

\author{
Rizki Dwi Lindawati ${ }^{1}$, Rindu ${ }^{2}$ \\ 1,2Program Studi Kesehatan Masyarakat \\ Sekolah Tinggi Imu Kesehatan Indonesia Maju \\ Gedung HZ Jl. Harapan No.50 Lenteng Agung Jakarta Selatan 12610 \\ Telp. (021) 788940444/45 Fax. (021) 78894045 \\ Email: rizkilindawati@gmail.com
}

\begin{abstract}
Abstrak
Pada masa remaja mereka akan mengalami masa yang penuh dengan perubahan, mereka harus dapat melewati masa transisi kehidupannya dengan baik dan tepat. Oleh sebab itu, agar remaja dapat melalui setiap transisi ini dengan baik salah satu syaratnya adalah memiliki keterampilan hidup (life skill). Keterampilan hidup (life skill) adalah kemampuan untuk berperilaku yang adaptif dan positif yang membuat seseorang dapat menyelesaikan kebutuhan dan tantangan sehari-hari dengan efektif. Tujuan penelitian ini adalah untuk mengetahui hubungan karakteristik, pengetahuan dan keterampilan hidup (life skill) remaja mengenai perilaku berpacaran pada mahasiswa jurusan psikologi di Universitas Gunadarma tahun 2015. Desain penelitian yang digunakan adalah kuantitatif dengan cross sectional, jumlah sampel pada penelitian ini adalah 30 responden. Hasil penelitian menunjukan bahwa pengalaman berpacaran, pekerjaan orang tua, dan pengetahuan responden memiliki hasil $\mathrm{p}$-value lebih besar dari 0,05 memberikan arti bahwa terdapat hubungan yang bermakna dengan perilaku berpacaran, sedangkan untuk usia, jenis kelamin, dan keterampilan hidup (life skill) tidak terdapat hubungan bermakna dengan perilaku berpacaran. Berdasarkan hasil penelitian maka penulis menyarankan kepada Universitas Gunadarma untuk bekerja sama dengan badan kesehatan seperti PKPR (Badan Kesehatan Peduli Remaja) untuk mendapatkan penyuluhan atau pengetahuan tentang kesehatan reproduksi.
\end{abstract}

Kata kunci : Keterampilan Hidup (Life Skill), Pengetahuan, Perilaku Berpacaran

\begin{abstract}
During adolescence they will have a full of change, they should be able to past the transition his life with nice and exact. Therefore, that teenagers can through each this transition with either one precondition to have life skills. Life skills is the ability to behave who adaptive and positive that make a person to finish the needs and challenges daily effectively. The purpose of this research is to find relations characteristic, knowledge and life skills teenagers regarding the date at the University of Gunadarma of psychology the second semester in 2015. Design research used is quantitative by crossing sectional, the sample of the to research this is 30 respondents. The results of the study showed that experience date, the work of old, and knowledge respondents having results p-value greater than 0.05 giving the meaning of that there was no correlation meaningful with the behavior date. While for age, sex, and life skill there was no correlation meaningful with the behavior date. Based on the research done hence writers suggest to University Gunadarma to cooperate with the health agency to like PKPR (Agency for Health Care for Teens) to obtain counseling or knowledge about reproductive health.

Keywords : Life Skills, Knowledge, Dating Behavior
\end{abstract}




\section{PENDAHULUAN}

Pada masa remaja mereka akan mengalami masa yang penuh dengan perubahan, baik itu pada dirinya maupun dalam hubungannya dengan lingkungan hidupnya, sehingga untuk mencapai upaya agar menjadi manusia yang berkualitas, mereka harus dapat melawati masa transisi kehidupannya dengan baik dan tepat. Oleh sebab itu, agar para remaja dapat melalui setiap transisi ini dengan baik maka salah satu prasyaratnya adalah memilki "Life Skills" atau ketrampilan/kecakapan hidup, agar mereka mempunyai kecerdasan, ketrampilan dan kemampuan dalam menyikapi dan menghadapi kehidupan ini, sehingga akan mempermudah baginya untuk dapat beradaptasi dan berperilaku positif yang memungkinkan seseorang mampu menghadapi berbagai tuntutan dan tantangan dalam kehidupan sehari-hari secara efektif. ${ }^{1}$

Jadi kesuksesan dalam kehidupan, tidak hanya ditentukan oleh prestasi akademik saja tapi juga oleh kemampuan dan ketrampilan dalam menghadapi berbagai masalah kehidupan. Respon dalam bentuk sikap dan perilaku positif terhadap pengaruh lingkungan, merupakan ketrampilan yang dapat diperoleh melalui penigkatan pengetahuan, dan latihan-latihan praktis dan mempraktikannya sehari-hari. ${ }^{1}$

Remaja akan tetap meminta pertimbangan dari orang tuanya ketika menghadapi masalah berat atau harus menentukan sesuatu yang berkaitan dengan masa depannya yang berakibat jangka panjang. Hal ini merupakan bentuk ketergantungan remaja kepada orang tua. Ketergantungan pada teman sebaya lebih mengarah pada hal-hal yang berkaitan denga relasi sosial atau penerimaan lingkungan (misalnya tingkah laku/kebiasaan sehari-hari, kesukaan, aktifitas yang dipilih, gaya bahasa, dan lainnya). ${ }^{2}$

Diterima oleh teman sebaya merupakan sesuatu yang sangat berarti bagi remaja, sehingga penyesuaian diri dengan kelompok, misalnya penyesuaian dengan selera, cara berpakaian, cara berbicara dan berperilaku sosial lainnya adalah penting. Remaja yang berasal dari keluarga yang terlalu hangat, memberikan perlindungan dan keamanan secara berlebihan, melibatkan ikatan emosi yang sangat kuat cenderung memengaruhi remaja menjadi malas menjalin ikatan lain diluar keluarga atau mengalami kesulitan dalam berinteraksi di lingkungan selain keluarganya. Umumnya remaja ini lebih senang menyendiri atau bergaul dengan orang-orang tertentu saja, ada juga yang menjadi minder sulit berinteraksi dengan sebayanya. Sementara keluarga yang tidak memberikan kehangatan dan ikatan emosi kepada anak, cenderung memengaruhi remaja berusaha keras meningkatkan diri pada lingkungan lain (yang berarti baginya) dan secara penuh mengikuti aturan kelompok tersebut (tanpa membedakan mana tingkah laku yang slah atau benar). ${ }^{2}$

Menurut survei yang terdapat pada Komnas Perlindungan Anak di 33 Provinsi Januari sampai dengan Juni 2008 didapatkan kesimpulan bahwa 97\% remaja SMP dan SMA pernah menonton film porno; $93,7 \%$ remaja SMP dan SMA pernah berciuman, genital stimulation (meraba alat kelamin) dan oral sex (sex melalui mulut); 62,7\% remaja SMP tidak perawan; dan $21,2 \%$ remaja pernah aborsi yang terjadi karena penyaluran dorongan seksual remaja kearah yang tidak Tepat. ${ }^{3}$

Survei oleh DKT Indonesia (salah satu perusahaan kontrasepri internasional yang beroperasi di Indonesia) yang dilaksanankan di daerah Jakarta, Bogor, Depok, Tangerang dan Bekasi (Jabodetabek), Bandung, Yogyakarta Surabaya dan Bali terhadap 663 responden pria dan wanita berusia $15-25$ tahun. Sebanyak 69, 6\% remaja (462 orang) mengaku telah berhubungan seks dan $31 \%$ diantaranya, merupakan mahasiswa, kemudian $18 \%$ karyawan kantor dan kelompok pedagang, pengusaha, buruh serta cukup meghawatirkan adalah ada $6 \%$ mereka mengaku telah berhubungan seks adalah masih berada di bangku SMP atau SMA. ${ }^{4}$

Berdasarkan hasil wawancara yang dilakukan peneliti, di Universitas Gunadarma diketahui bahwa 10 dari 20 mahasiswa mengatakan pernah berpacaran di luar 
ataupun di lingkungan kampus. Mereka mengatakan tidak merasa malu apabila memiliki pacar dan berpacaran di lingkungan kampus serta mengumbar kemesraan di lingkungan kampus. 5 mahasiswa diantaranya mengatakan pernah berciuman dan berpelukan namun tidak dilingkungan kampus. Menurut mereka hal ini sudah biasa dilakukan karena mereka menggangap hal itu merupakan salah satu ekspresi untuk menunjukan rasa suka dan sayang terhadap pasangan. 15 mahasiswa diantaranya mengatakan mereka berpacaran sudah diberi ijin oleh orang tua mereka. Orang tua mereka memberikan kebebasan untuk bergaul dengan siapa saja termasuk memiliki pasangan asalkan bukan bergaul dengan sembarang orang serta dinasehati dan mendapat larangan pergaulan bebas. Peran keluarga dalam perilaku pacaran sehat dengan melakukan pengawasan pergaulan dalam bentuk nasihat untuk menjaga diri. Mereka mengatakan selama itu tidak melebihi batas norma yang negatif mereka diperbolehkan untuk memiliki pasangan. Namun banyak diantaranya mengatakan bahwa orang tua mereka terkadang terlalu sibuk dengan aktifitas pekerjaan mereka sehingga jarang ada dirumah dan mereka jarang menceritakan aktifitas di lingkungan kampus termasuk tentang memiliki pasangan.

Dengan permasalahan diatas peneliti tertarik untuk melakukan penelitian mengenai hubungan karakteristik, pengetahuan dan ketrampilan hidup (life skill) remaja mengenai perilaku berpacaran. Karena sangat pentingnya remaja mengetahui bagaimana berpacaran yang seharusnya agar tidak menyesal pada akhirnya maka dirasakan perlu diadakan penelitian mengenai hal ini.

Tujuan penelitian ini adalah untuk mengetahui bagaimana hubungan antara karakteritistik (usia, jenis kelamin, pengalaman berpacaran, dan pekerjaan orang tua), pengetahuan dan keterampilan hidup (life skill) dengan perilaku berpacaran mahasiswa di Universitas Gunadarma tahun 2015
METODE

Jenis penelitian yang digunakan adalah penelitian kuantitatif dengan menggunakan metode potong lintang (cross sectional). Penelitian ini dilakukan di Universitas Gunadarma kampus J5, Cakung pada tanggal 13 Agustus 2015. Adapun populasi dalam penelitian ini adalah mahasiswa/I Universitas Gunadarma jurusan psikologi semester dua yang berjumlah 80 mahasiswa/I yang berada kampus J5 Cakung. Pengambilan sampel pada penelitian ini menggunakan teknik random sampling. Sampel yang digunakan adalah sebagian populasi yang akan diteliti yaitu mahasiswa Universitas Gunadarma jurusan psikologi semester dua di kampus J5, Cakung yang mengikuti ujian akhir semester yang berlangsung pada tanggal 30 Agustus 2015 yaitu berjumlah 30 siswa.

Kriteria inklusi dalam penelitian ini adalah (1) Tercatat sebagai mahasiswa/I Universitas Gunadarma kampus J5 yang berada di Cakung yang mengikuti ujian akhir semester. (2) Bersedia menjadi responden. Kriteria Eklusi dalam penelitian ini adalah (1) Menolak untuk diikutsertakan dalam penelitian. (2) Mahasiswa/I tidak mengikuti ujian saat pengambilan sampel karena absen atau sakit.

Uji coba dilakukan terhadap 20 mahasiswa/I yang mengikuti Ujian Tengah Semester. Pada penelitian uji validitas ini, menggunakan alat bantu pengolahan SPSS Statistic Windows Versi 18. Hasil uji validitas didapatkan 34 dari 45 pernyataan dinyatakan valid. Dengan hasil $r$ tabel $=0,38$.

\section{HASIL}

Penyajian hasil penelitian dimulai dengan gambaran analisis univariat yang bertujuan untuk melihat distribusi variabel. Sedangkan analisa bivariat untuk melihat pengaruh antara variabel.

Dari hasil penelitian analisa univariat didapatkan bahwa usia remaja pada usia 17 tahun sebanyak 3 responden (10\%), usia 18 tahun sebanyak 13 responden $(43,3 \%)$ dan usia 19 tahun sebanyak 14 responden (46,7\%). Pada distribusi jenis kelamin sebanyak 12 responden (40\%) yaitu laki-laki 
sedangkan perempuan sebanyak 18 responden (60 \%). Pengalaman berpacaran remaja sebanyak satu kali ada 9 responden $(30 \%)$, dua kali berpacaran sebanyak 13 responden $(43,3 \%)$ dan tiga kali berpacaran sebanyak 8 responden $(26,7 \%)$. Pada distribusi pekerjaan orang tua terdapat tiga pekerjaan yaitu sebagai PNS (Pegawai Negeri Swasta), pegawai swasta dan wiraswasta, untuk pekerjaan orang tua responden sebagai PNS sebanyak 8 responden $(26,7 \%)$, sebagai pegawai swasta sebanyak 16 responden $(53,3$ $\%)$ dan sebagai wirausaha sebanyak 6 responden $(20 \%)$.

Tabel 1. Distribusi Karakteristik Responden

\begin{tabular}{llll}
\hline Variabel & Kategori & n & \% \\
\hline Usia & 17 tahun & 3 & 10 \\
& 18 tahun & 13 & 43,3 \\
Jenis kelamin & 19 tahun & 14 & 46,7 \\
& Laki-laki & 12 & 40 \\
Pengalaman & Perempuan & 18 & 60 \\
berpacaran & 1 kali & 9 & 30 \\
& & & \\
Pekerjaan orang tua & 2 kali & 13 & 43,3 \\
& 3 kali & 8 & 26,7 \\
& PNS & 8 & 26,7 \\
& Pegawai Swasta & 16 & 53,3 \\
& Wiraswasta & 6 & 20 \\
\hline
\end{tabular}

Tabel 2. Hubungan Karakteristik, Pengetahuan dan Keterampilan Hidup (Life Skill) Remaja Tentang Perilaku Berpacaran

\begin{tabular}{ll}
\hline Variabel & P.value \\
\hline Usia & 0,569 \\
Jenis kelamin & 0,317 \\
Pengalaman berpacaran & 0,029 \\
Pekerjaan orang tua & 0,020 \\
Pengetahuan & 0,014 \\
Life skill & 0,177 \\
\hline
\end{tabular}

Hasil uji analisa bivariat antara variabel usia dengan perilaku berpacaran didapatkan $\mathrm{p}$-value $=0,569$ lebih besar dari $\alpha=0,05$ memberikan arti bahwa tidak terdapat hubungan antara usia dengan perilaku berpacaran.

Hasil uji analisa bivariat antara variabel jenis kelamin dengan perilaku berpacaran didapatkan $\mathrm{p}$-value $=0,317$ lebih besar dari $\alpha$ $=0,05$ memberikan arti bahwa tidak terdapat hubungan bermakna antara jenis kelamin dengan perilaku berpacaran.

Hasil uji analisa bivariat antara pengalaman berpacaran dengan perilaku berpacaran didapatkan p-value $=0,029$ lebih kecil dari $\alpha=0,05$ memberikan arti bahwa terdapat hubungan antara pengalaman berpacaran dengan perilaku berpacaran.

Hasil uji analisa bivariat antara pekerjaan orang tua dengan perilaku berpacaran didapatkan $\mathrm{p}$-value $=0,020$ lebih kecil dari $\alpha=0,05$ memberikan arti bahwa terdapat hubungan bermakna antara pekerjaan orang tua dengan perilaku berpacaran.

Hasil uji analisa bivariat antara pengetahuan responden dengan perilaku berpacaran didapatkan $\mathrm{p}$-value $=0,014$ lebih kecil dari $\alpha=0,05$ memberikan arti bahwa terdapat hubungan antara pengetahuan responden dengan perilaku berpacaran. Nilai OR menunjukan nilai 6,0 yang artinya responden yang memiliki pengetahuan tinggi memiliki peluang sebesar 6,0 (6) kali berpeluang untuk perilaku berpacaran positif.

Hasil uji analisa bivariat antara keterampilan hidup (life skill) responden dengan perilaku berpacaran didapatkan pvalue $=0,177$ lebih besar dari $\alpha=0,05$ memberikan arti bahwa tidak terdapat hubungan antara keterampilan hidup (life skill) responden dengan perilaku berpacaran.

\section{PEMBAHASAN}

Penelitian ini secara konseptual baru memakai 3 variabel. Penelitian ini hanya mengunakan analisis biavariat dan belum menggunakan analisis multivariat. Masih mengunakan metode kuantitatif dengan mengunakan desain cross sectional, pada peneltian ini masih banyak kelemahan dimana masih sedikitnya informasi yang dapat digali secara dalam dari remaja tentang perilaku dalam berpacaran. Sampel yang digunakan peneliti hanya 30 responden saja. Hal ini belum mencakup populasi yang ada yaitu sebesar 80 mahasiswa jurusan psikologi di Universitas Gunadarma. Uji validitas yang telah dilakukan dan direvisi kembali pada kuesioner, tidak dilakukan kembali uji 
validitas dikarenakan keterbatasan waktu penelitian.

\section{Karakteristik Responden}

Hasil analisis hubungan antara usia responden dengan perilaku berpacaran, didapatkan bahwa $12(87,5 \%)$ responden berusia 19 tahun masuk kategori perilaku berpacaran baik. Hasil analisis bivariat pada penelitian ini bahwa tidak terdapat hubungan bermakna antara usia dengan perilaku berpacaran yang mana $p$-value $=0,569$ lebih besar dari $\alpha=0,05$. Faktor umur penting sekali. Makin lanjut usia pemuda pemudi, diharapkan mereka juga lebih memperlihatkan kematangan. Taraf kematangan ini perlu supaya remaja dapat mempertimbangkan dengan baik sifat dan tingkat pacaran dalam hubungannya dengan batas-batas kesopanan ${ }^{5}$ Terdapat $14(77,8 \%)$ responden perempuan masuk kategori perilaku berpacaran baik dan untuk jenis kelamin laik-laki $11(91,7 \%)$. Hasil uji analisa bivariat pada penelitian ini tidak terdapat hubungan bermakna antara jenis kelamin dengan perilaku berpacaran yang mana didapatkan p-value $=0,317$ lebih besar dari $\alpha$ $=0,05$. Disimpulkan bahwa perempuan cenderung menghindar perilaku berpacaran yang berlebihan agar tetap menjaga suatu hubungan, namun penelitian yang dilakukan oleh Rony Setiawan ${ }^{6}$ bahwa kelompok lakilaki lebih permisif/lebih menyetujui melakukan perilaku seksual pranikah dengan pasangan dibandingkan dengan kelompok remaja perempuan. Untuk pengalaman berpacaran sebanyak 9 responden (100\%) pernah berpacaran sebanyak 1 kali dengan perilaku berpacaran baik. Berdasarkan hasil uji analisa bivariat antara pengalaman berpacaran dengan perilaku berpacaran didapatkan $p$-value $=0,029$ lebih kecil dari $\alpha$ $=0,05$ memberikan arti bahwa terdapat hubungan bermakna antara pengalaman berpacaran dengan perilaku berpacaran. Pada penelitian yang dilakukan oleh Fridya ${ }^{7}$ mengatakan bahwa faktor frekuensi berganti pacar mempunyai pengaruh yang cukup berarti terhadap peranan harga diri dengan perilaku seksual dalam berpacaran terutama bagi remaja. Untuk pekerjaan orang tua responden sebanyak 13 responden memiliki orang tua yang bekerja sebagai pegawai swasta $(86,7 \%)$. Berdasarkan hasil uji analisa bivariat antara pekerjaan orang tua dengan perilaku berpacaran didapatkan $\mathrm{p}$-value $=$ 0,020 lebih kecil dari $\alpha=0,05$ memberikan arti bahwa terdapat hubungan bermakna antara pekerjaan orang tua dengan perilaku berpacaran. Penelitian menurut Dhian ${ }^{8}$ orang tua yang bekerja biasanya waktu yang disediakan untuk anak lebih sedikit dari pada waktu di luar rumah sehingga kontak dengan anak menjadi berkurang.

\section{Hubungan Pengetahuan Dengan Perilaku Berpacaran}

Hasil analisis hubungan pengetahuan responden dengan perilaku berpacaran didapatkan bahwa perilaku berpacaran yang positif terdapat $15(93,8 \%)$ responden yang berpengetahuan tinggi. Hasil uji analisa bivariat antara pengetahuan responden dengan perilaku berpacaran didapatkan $\mathrm{p}$-value $=$ 0,014 lebih kecil dari $\alpha=0,05$ memberikan arti bahwa terdapat hubungan bermakna antara pengetahuan responden dengan perilaku berpacaran. Pengetahuan diperlukan sebagai dukungan dalam menumbuhkan rasa percaya diri maupun sikap dan perilaku setiap hari, sehingga dapat dikatakan bahwa pengetahuan merupakan fakta yang mendukung tindakan seseorang. ${ }^{9}$

\section{Hubungan Keterampilan Hidup (Life Skill) Dengan Perilaku Berpacaran}

Hasil analisis hubungan keterampilan hidup (life skill) responden dengan perilaku berpacaran didapatkan bahwa perilaku berpacaran baik terdapat $18 \quad(73,3 \%)$ responden sudah memiliki keterampilan hidup tinggi. Hasil uji analisa bivariat antara keterampilan hidup (life skill) responden dengan perilaku berpacaran didapatkan pvalue $=0,177$ lebih besar dari $\alpha=0,05$ memberikan arti bahwa tidak terdapat hubungan bermakna antara keterampilan hidup (life skill) responden dengan perilaku berpacaran. Penelitian yang dilakukan oleh Fitriyatun $^{10}$ yang didalamnya membahas 
tentang proses peningkatan keterampilan hidup (life skill) dengan menerapkan pendidikan berbasis luas dengan melakukan pendidikan life skill melalui orientasi pembelajaran penciptaan hubungan dengan masyarakat dan pengisian muatan pendidikan yang sesuai dengan kebutuhan mayarakat agar pembelajaran lebih demokratis.

\section{KESIMPULAN}

Berdasarkan hasil dan pembahasan penelitian yang telah dilakukan terdapat beberapa kesimpulan bahwa pada karakteristik responden untuk variabel usia, jenis kelamin tidak memiliki hubungan dengan perilaku berpacaran di Universitas Gunadarma tahun 2015, sedangkan pengalaman berpacaran dan pekerjaan orang tua memiliki hubungan dengan perilaku berpacaran di Universitas Gunadarma tahun 2015. Untuk hasil pembahasan pada variabel pengetahuan, didapatkan bahwa terdapat hubungan pengetahuan dengan perilaku berpacaran di Universitas Gunadarma, tahun 2015. Sedangkan, pada keterampilan hidup (life skill) tidak memiliki hubungan dengan perilaku berpacaran di Universitas Gunadarma tahun 2015.

\section{SARAN}

Kepada Universitas Gunadarma diharapkan untuk bekerja sama dengan badan kesehatan seperti PKPR (Badan Kesehatan Peduli Remaja) untuk mendapatkan penyuluhan atau pengetahuan tentang kesehatan reproduksi. Serta lebih memfokuskan program wali kelas untuk mendekatkan mahasiswa dengan dosen pebimbingnya agar mahasiswa dapat mengembangkan kegiatan yang positif serta proses belajar yang kondusif dan mengontrol kegiatan remaja di lingkungan kampus.

\section{DAFTAR PUSTAKA}

1. Kementerian Kesehatan RI. Modul pelatihan pelayanan kesehatan peduli remaja (pkpr) bagi konselor. Jakarta; 2011.

2. Kusmiran, E. Kesehatan reproduksi remaja dan wanita. Jakarta: Salemba Medika; 2012
3. BKKBN. Menurut Survey kesehatan reproduksi tentang persen perilaku remaja berpacaran dengan gaya berpacaran. 2009

4. 2012. Remaja yang pernah berhubungan intim melakukannya di usia 19 tahun http://www.republika.co.id/berita/nasional/u mum/11/12/05/remaja-yang-pernahberhubungan-intim-melakukannya-di-usia19-tahun [2 Juli 2015]

5. Kurniawati, N. Perilaku berpacaran pada remaja usia madya: studi kasus di kabupaten merangin jambi. Universitas Muhammadiyah [Studi Kasus]. Surakarta; 2012.

6. Setiawan R. Pengaruh pacaran terhadap perilaku seks pranikah. [Jurnal]. 2008.

7. Mayasari F. Perilaku seksual remaja dalam berpacaran ditinjau dari harga diri berdasarkan jenis kelamin. [Jurnal Psikologi]. Yogyakarta: Universitas Gajah Mada; 2000.

8. Luluh D. Pengetahuan orang tua mengenai perilaku berpacaran anak dan remajanya dan perannya dalam memberikan pendidiakn seks di desa kepuhrejo kecamatan takeran magetan jawa timur. [Skripsi]. Universitas Indonesia; 2012.

9. Notoadmojo S. Ilmu perilaku kesehatan. Jakarta: Rineka Cipta; 2014.

10. Khasanah F. Upaya pesantren berbasisi agribisnis dalam meningkatkan life skill santri pondok pesantren pada tahun 2012. [Skripsi]. Semarang : Fakultas Institut Agama Islam Negeri Walisongo; 2012 